\title{
Measuring Work Engagement On IT Worker in Indonesia
}

\author{
Rahma Fitriani ${ }^{1}$, Rina Anindita ${ }^{2}$ \\ Esa Unggul University, Jakarta, Indonesia ${ }^{1,2}$
}

\begin{abstract}
The purpose of this study to To be able to find a picture of low and high work engagement of each employee, to be able to know the description of work engagement is characterized by vigor, dedication and absorption, to be able to determine the relationship work engagement of employees in the division of IT and Non IT To determine the relationship by Vigor, dedication and absorption of employees in the IT and Non IT divisions. The research method used in this study is by collecting data by distributing questionnaires as many as 370 respondents who are IT and Non IT divisions from September to December 2018 in information technology companies in Jakarta, Indonesia. The analytical method used is a questionnaire that has been tested using validity test, reliability test and also categorizing and different tests. The results of this study indicate the research model in accordance with the sample data used. Data on the highest percentage of respondents from the age of $20-30$ who are more male sex with unmarried relationship status as private workers. For the division of work in information technology companies, it is more likely for the IT division, which mostly works as a network engineer and front end. and employees mostly work for 2 years . For categorizing work engagement in companies in the information technology sector tends to be high, then for vigor it tends to be lower than dedication and absorption. Whereas in the IT and Non IT divisions, IT vigor tends to be lower than Non IT, for IT and Non IT dedication tends to be high, then for absorption in IT division tends to be high compared to Non IT which tends to be low. And there are no significant differences in the level of work management, set of vigor, dedication, and absorptions related to the IT and Non IT divisions.
\end{abstract}

Keywords: Work Engagement, Vigor, Dedication, Absorption, IT Division, Non IT Division

\section{INTRODUCTION}

Every organization needs to think about and have strategies, innovations, and certain processes to maintain existing human resources. One of them is by creating a conducive work environment for workers so that each member of the organization has a sense of attachment to his organization or known as employee engagement. Work engagement , the level of involvement of a worker marked by passion, dedication and high appreciation in doing their work (Taranowski, 2011), important for a company or organization. According to Aini, Hardjajani and Priyatama (2014) high quality of work life is interpreted as a systematic effort of the company to provide good opportunities for employees to develop and influence their work, as well as opportunities to contribute to organizational effectiveness in the company as a whole.

Bakker, Schaufali, Leiter, and Taris (2008) work engagement doing his work, such as devoting most of his time to working and trying, looking for something meaningful in his work and enjoying his work so that workers forget the time when doing their work. Employee engagement is claimed to be able to predict an increase in employee productivity, profitability, employee retention, customer satisfaction and success for the organization. Trend Employee engagement in Indonesia has shown a steady increase in engagement scores demonstrated by a consistent increase of $64 \%$ to $71 \%$ over the past 6 years, this is the highest engagement score among 11 Asia Pacific countries. Best employers in Indonesia achieved a growth rate of $4 \%$ higher than other companies, best employers in Indonesia enjoy engagement scores significantly higher than their employees (89\%) (humancapital, 2014). According to Agnes and Roy (2017) There is also an Employee engagement that has a positive and significant effect on the performance of employees at PT Tirta Rejeki Dewata. So that it can be said that increasing employee engagement can improve employee performance

Work engagement must be a serious concern by executives in the field of human resources and top executives so that companies can survive the impact of the current global crisis.. This opinion is also reinforced by several studies that correlate the high work engagement with the achievement of company targets, and the results are very positive. Work engagement discourse is usually always associated with talent management, which some companies still consider to be a high-cost program, although the results will be very beneficial in the long term (Agustian, 2012). The magnitude of the benefits of work engagement makes it an important topic to be developed so that the maximum level of engagement 


\title{
International Advanced Research Journal in Science, Engineering and Technology
}

\author{
Vol. 6, Issue 3, March 2019
}

can be obtained by considering variables that can support engagement . for example in several studies it has been found that the relationship between self-efficacy and work engagement is a predictor of work engagement.

Bakker (2011) explains that employees with high work engagement are more likely to work harder and have more positive emotions such as being grateful, happy and enthusiastic about their work than employees with low work engagement. In each company each division must have high or low work engagement. Work engagement refers to the conditions of cognition (absorption) and growing spirit. So that working engagement is a good predictor of job performance. On high engagement, makes employees very motivated in their work and have commitment, enthusiasm and enthusiasm (Mujiasih, 2015). Employees who have high levels or levels of attachment to both domestic and global organizations will increase retention, strengthen loyalty and improve organizational performance (Tintien, 2016).

The researcher took the opportunity to conduct research in a company engaged in the information engineering industry in the South Jakarta area to find out the description of work engagement which was viewed from the IT and Non IT divisions. Having a clear picture of work engagement with the company and their work will help not only the company in achieving organizational goals but also employees in realizing the importance of their role in their work. The results of this study can also guide management in formulating human resource policies and programs for workers that have work engagement. The goal is to be able to find a picture of low and high work engagement of each employee, to be able to know the description of work engagement is characterized by vigor dedication and absorption, to be able to determine the relationship work engagement of employees in the division of IT and Non IT and To determine the relationship by vigor, dedication and absorption of employees in the IT and Non IT divisions. Comparisons are made based on grouping namely age, gender, employee status, employee employment, division of work, part of the work and also long time working.

\section{LITERATURE REVIEW}

Schaufeli and Bakker (2004) define work engagement as a condition satisfied and happy souls related to work, characterized by enthusiasm, dedication, and appreciation. The concept of employee engagement began to be widely used as a solution in the work environment, especially if it is related to motivation and performance. In addition, Saks (2006) states that work engagement can predict employee work outcomes, organizational success, and performance. Field and Buitendach (2011) found that work engagement has a strong relationship with happiness and organizational commitment.

Work engagement it is also a feeling of emotional attachment to work and organization, motivated and able to provide the best ability of employees to help the success of a series of tangible benefits for organizations and individuals (McLeod, 2009) . Employee engagement is the attachment of members of the organization to the organization itself not only physically, cognitively but even emotionally in terms of performance (Albrecht, 2010). Employee engagement is an idea in organizational behavior that has become an attraction in recent years. This attraction arises because employee engagement affects the overall performance of employees. This has been defined by one of the leading research organizations as a high emotional relationship that an employee feels towards the organization that influences it to mobilize a free and greater effort for his work (Risher, 2010).

Schaufeli \& Bakker (2010) employees who have work high engagement will consistently demonstrate three general behaviors, namely Say - consistently speak positively about the organization where he works with colleagues, potential employees and also customers, Stay - Has the desire to become a member of the organization where he works rather than the opportunity to work in other organizations and Strive - Providing more time, energy and initiative to be able to contribute to the organization's business success. Schaufeli \& Bakker (2010) defines employee engagement as a positive attitude, full of meaning, and motivation, characterized by vigor, dedication , and absorption . Vigor is characterized by high energy levels, resilience, the desire to try, and not give up in the face of challenges. Dedication is characterized by feeling valuable, enthusiastic, inspiring, valuable and challenging. Absorption is characterized by full concentration on a task.

Work engagement features According to Finney (2010) employees who have a bond with their work have a general nature of believing in their organization's mission, Enjoying their work and understanding their work contributions to a larger purpose, Do not require disciplines and they only need clarity, communication, and consistency, always improve the truth of their skills with a positive attitude, focus, desire, enthusiasm , creativity, and endurance, trustworthy and trust each other, respecting their manager, knowing that their manager respects them , is a permanent source great new ideas and the last is to give the best to the organization.

Some concepts related to work engagement, including Extrarole behavior, Workaholism, Organizational commitment, Organizational Citizen Behavior and Job Involvement. Extra role behavior, Even though work engagement is usually defined as discreationary effort or going extra mile, engagement is different from the concept of extra role behavior . 


\title{
International Advanced Research Journal in Science, Engineering and Technology
}

\author{
Vol. 6, Issue 3, March 2019
}

Work engagement provides something different on the job, not just doing things excessively, for example working for hours (Schaufeli \& Bakker, 2010).

Bakker and Demerouti (2008) there are three main causes of work engagement, among others, Job Resources that the Job resources refers to the physical aspects, social, and organizational of peerjaan that allows individuals to reduce the demands of work and the cost of both psychology and physiology since late circuitry jobs the m encapai targets, and menstimulusi the growth and personal development., Salience of Job Resources, namely this factor refers to how important or useful the work resources possessed by individuals. and Personal Resources, namely Personal resuscitation refers to characteristics possessed by employees such as personality, nature, age, etc. Engaged employees will have personal characteristics that are different from other employees because they have higher extraversion scores and conscientiousness, and lower neuroticism.

\section{Framework and Development Hypothesis}

This study looked at the work engagement picture of employees in the IT and Non IT divisions by considering age, gender, employee status, employment, division of work, part of the work and also the length of work, and the concept of thinking taken from several previous studies, according to Winoto Sugiarto, P. Tommy YS Suyasa and Daniel Lie (2017) at PT. X, in particular the Information Technology (IT) work unit, found several events that show that work engagement is not too high from employees. Vigor, dedication, absorption which is a dimension of work engagement can be seen in the daily lives of employees. And according to Shabrina and Mardiawan (2017) in the marketing and operational division, work engagement with a low category.

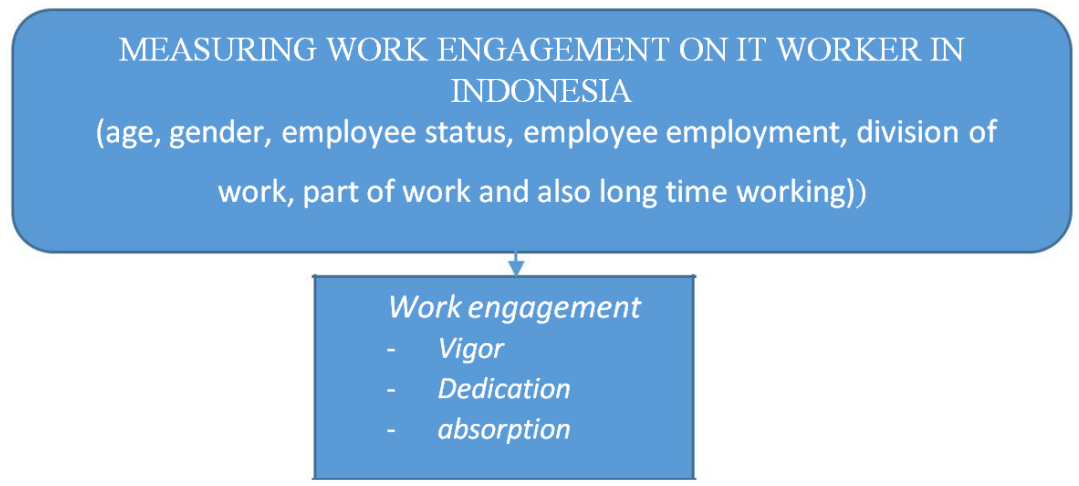

Figure 1. Schematic diagram

For the hypothesis obtained, it is assumed that there is a low work engagement in the IT and Non IT divisions.

\section{RESEARCH METHOD}

This study includes quantitative research with descriptive methods, which is concerned with the question of the existence of independent variables, both only on one variable or more Sugiyono (2014). Aim to see how far. In this study the researchers looked for a picture of work engagement in the information technology industry reviewed from IT and non IT divisions. The population in this study is the population of company employees in the field of information engineering who work in the IT division and non-IT South Jakarta region with a total of 123 companies. but researchers only conducted research in 20 companies. This data the researcher obtained by giving a questionnaire. Data collection techniques are ways that are done to obtain data and information needed in research. In the questionnaire there are statements about vigor, dedication and absorption. In this study the researcher determined the number of samples using the Krejcie and Morgan tables. For an uncountable population, the number of samples taken is 370 respondents. Calculations are obtained if the total population is 10,000 with an error rate of $5 \%$ which results in a total sample of 370 respondents. Data analysis used is validity test, reliability test, categorization by determining the mean and deviation values first, and the last one using the T test.

\section{RESULTS AND DISCUSSION}

Measurements in Work Engagement variables related to IT and Non IT divisions, Work Engagement dimensions , vigor related to IT and non IT divisions, dedication related to IT and non IT divisions, and Absorption related to IT and non IT divisions using 5 levels. Measurements with 5 levels are divided into: very low, low, medium, high, and very high. The 5 level measurements are calculated using statistical software and also for calculations obtained using the mean and standard deviation values. 


\title{
International Advanced Research Journal in Science, Engineering and Technology
}

\author{
Vol. 6, Issue 3, March 2019
}

Work Engagement . The following frequency of calculation results based on the above categorization determination formula is divided into 5 categorizations at the level of work engagement in the IT and Non IT divisions. For details, see the table

Table 1: Work engagement categorization in the IT and Non IT divisions

\begin{tabular}{|c|c|c|c|}
\hline Categorization & Total & IT & Non IT \\
\hline Very low & $10.5 \%$ & $9.2 \%$ & $7.1 \%$ \\
\hline Low & $11.9 \%$ & $10.7 \%$ & $25.5 \%$ \\
\hline Neutral & $48.9 \%$ & $48.5 \%$ & $33.7 \%$ \\
\hline High & $24.1 \%$ & $29.4 \%$ & $28.6 \%$ \\
\hline Very high & $4.6 \%$ & $2.2 \%$ & $5.1 \%$ \\
\hline Total & $100 \%$ & $100 \%$ & $100 \%$ \\
\hline
\end{tabular}

Source: results of quizione data processing

The highest work engagement is found in moderate categorization, the percentage is $48.9 \%$ and the lowest is very high categorization with $4.6 \%$ percentages. Whereas in the number of counts between very low and low, which is $22.4 \%$, and for the addition of high and very high, which is $28.7 \%$. So, it can be seen that categorization with the highest percentages is in the high and very high summation categories. Then it can be seen in the IT and non IT divisions, the highest is the IT division which is in the medium categorization which is $48.5 \%$ and for non-IT divisions as well. in the medium categorization with a percentage of $33.7 \%$ and for the lowest in the IT division that is very high categorization with $2.2 \%$ and for non IT it is also the lowest in very high categorization with $5.1 \%$. Whereas in the count the number between very low and low in the IT division is $19.6 \%$ and the Non IT division is $32.6 \%$. For high and very high addition in the IT division that is $31.6 \%$ and non IT divisions, namely $33.7 \%$. So, it can be seen that categorization with the highest percentages is in the IT division $31.6 \%$ and for non-IT $33.7 \%$ with high and very high addition categorization. From the explanation above, it can be interpreted that every employee who works in a company in the field of information technology has a work engagement that tends to be high. And this work engagement itself is different between employees who are IT and non IT divisions. This difference can be influenced by the age of employees who tend to be young, and can also be affected by the length of time the employee works. However, from the IT and non IT divisions for work engagement the highest is in the non IT division. It is in the non-IT division with a fairly young age, and have a sense of enthusiasm, enthusiasm, and appreciation in doing the work they do, one example of this aims to meet the personal needs of those who are still in school while working, earning income for Further education can be continued. From the research according to Agustian (2012) high work engagement makes a person motivated to work and has commitment, enthusiasm, competence, and enthusiasm. Work engagement makes someone's existence in a company or organization meaningful to their lives to touch the deepest level which at the end will improve the performance of the company or organization. So And from the results of the research, the hypothesis is rejected because the result is that it works engagement tends to be higher in the IT and Non IT divisions

Work Engagement Dimention. The following frequency of calculation results based on the above categorization determination formula is divided into 5 categorizations at the level of vigor, dedication and absorption. For details, see the table

Table 2: Categorization of Work Engagement Dimensions

\begin{tabular}{|l|l|l|l|}
\hline $\begin{array}{l}\text { Categorization } \\
\text { Very low }\end{array}$ & $\begin{array}{l}\text { Vigor } \\
5.7 \%\end{array}$ & $\begin{array}{l}\text { Dedication } \\
11.9 \%\end{array}$ & $\begin{array}{l}\text { Absorption } \\
8.4 \%\end{array}$ \\
\hline Low & $28.4 \%$ & $15.4 \%$ & $19.5 \%$ \\
\hline Neutral & $37.0 \%$ & $44.3 \%$ & $43.2 \%$ \\
\hline High & $22.4 \%$ & $24.3 \%$ & $25.7 \%$ \\
\hline Very high & $6.5 \%$ & $4.1 \%$ & $3.2 \%$ \\
\hline Total & & & $100 \%$ \\
\hline
\end{tabular}

Source: results of questionnaire data

in the highest vigor dimension, there is a moderate categorization, the percentage is $37.0 \%$ and the lowest is very low categorization with a percentage of $5.7 \%$. Whereas the count is very low and low, which is $34.1 \%$, and for high and very high sums of $28.9 \%$. So, it can be seen that categorization with the highest percentage is in the very low and low addition categorization. Then it can also be seen in the dimension of the highest categorization of dedication , namely there is a medium categorization with a percentage of $44.3 \%$ and the lowest is very high categorization with a percentage of $4.1 \%$. Whereas in the number of counts between very low and low, namely $27.3 \%$, and for the addition of high and very high at $28.4 \%$. So, it can be seen that categorization with the highest percentage is in the very high and 


\title{
International Advanced Research Journal in Science, Engineering and Technology
}

\author{
Vol. 6, Issue 3, March 2019
}

high addition categorization. And it can be seen in the highest categorization absorption dimension, which is found in the medium categorization, where the percentage is $43.2 \%$ and the lowest is very high categorization with a percentage of $3.2 \%$. Whereas in the count the number is very low and low, which is $27.9 \%$, and for the addition of high and very high, which is $28.9 \%$. So, it can be seen that categorization with the highest percentage is in the very high and high addition categorization.

From the explanation above, it can be interpreted that each employee has a vigor, which is different from dedication and absorption. From the vigor dimension it can be seen that the highest categorization is dominantly low. This can be confirmed because there are still many employees who are lazy to come to work and work. but the dimensions of dedication and absorption for categorization are more dominant, namely high categorization. This is due to factors from employees who consider their work to inspire themselves and also feel that work goes away while working. According to Meirlyn and Hana (2016) in the vigor dimension, it should be noted that the proportion of employees in the low category. This also shows that employees who lack the willingness to try to do more work than employees who have the enthusiasm and courage to get the job done

Vigor on IT and Non IT division. The following frequency of calculation results based on the categorization determination formula above, is divided into 5 categorizations at the level of vigor in the IT and Non IT divisions. For details, see the table

Table 3: Categorization of Differences in Vigor Levels in IT and Non IT divisions

\begin{tabular}{|l|l|l|}
\hline Categorization & IT Vigor & NonIT Vigor \\
\hline Very low & $8.8 \%$ & $6.1 \%$ \\
\hline Low & $27.7 \%$ & $26.5 \%$ \\
\hline Neutral & $40.8 \%$ & $33.7 \%$ \\
\hline High & $18.0 \%$ & $25.5 \%$ \\
\hline Very high & $6.6 \%$ & $8.2 \%$ \\
\hline Total & $100 \%$ & $100 \%$ \\
\hline
\end{tabular}

Source: results of questionnaire data

in the highest IT vigor dimension, there is a moderate categorization, the percentage is $40.8 \%$ and the lowest is very high categorization with a percentage of $6.6 \%$. Whereas in the count the number is very low and low, which is $36.5 \%$, and for the addition of high and very high, which is $24.3 \%$. So, it can be seen that categorization with the highest percentage is in the very low and low addition categorization. Then it can be seen in the highest non categorization of vigor categorization which is found in the categorization medium, the percentage is $33.7 \%$ and the lowest is very low categorization with percentages of $6.1 \%$. Whereas in the number of counts between very low and low, namely $32.2 \%$, and for high and very high sums of $33.7 \%$. So, it can be seen that categorization with the highest percentage is in the very high and high addition categorization. It can be interpreted that the number of percentages in IT vigor is predominantly low categorization. Which means employees in the division have a low sense of enthusiasm. This characteristic can be demonstrated by lack of zeal in the morning, doing work in idleness, and can also be affected by the background they have as IT but in attitudes and traits unlike IT people and there is no sense of resilience in doing work. As for the number of percentages in non IT vigor, the higher the categorization is dominant, this can be caused by employees having a high sense of responsibility and enthusiasm, and can also be caused because employees who are high school graduates are still passionate about finding jobs that can be a factor for tuition fees.

Dedication on IT and Non IT division. The following frequency of calculation results based on the above categorization determination formula is divided into 5 categorizations on the level of dedication in the IT and Non IT divisions. For details, see the table

Table 4: Categorization of Differences in Dedication Levels in IT and Non IT divisions

\begin{tabular}{|l|l|l|}
\hline Categorization & IT Dedication & NonIT Dedication \\
\hline Very low & $9.2 \%$ & $9.2 \%$ \\
\hline Low & $14.0 \%$ & $22.4 \%$ \\
\hline Neutral & $50.7 \%$ & $33.7 \%$ \\
\hline High & $20.6 \%$ & $27.6 \%$ \\
\hline Very high & $5.5 \%$ & $7.1 \%$ \\
\hline Total & $100 \%$ & $100 \%$ \\
\hline
\end{tabular}

Source: results of questionnaire data 


\title{
International Advanced Research Journal in Science, Engineering and Technology
}

\author{
Vol. 6, Issue 3, March 2019
}

on the highest IT dedication dimension, there is a medium categorization with a percentage of $50.7 \%$ and the lowest is very high categorization with a $5.5 \%$ percentage. Whereas in the count the number is very low and low, which is $23.2 \%$, and for the addition of high and very high, which is $26.1 \%$. So, it can be seen that categorization with the highest percentage is in the very high and high addition categorization. Then it can be seen in the Non IT dimension the highest categorization dedication is that there is a medium categorization with a percentage of $33.7 \%$ and the lowest is very high categorization with a percentage of $7.1 \%$. Whereas in the number of counts between very low and low, which is $31.6 \%$, and for the addition of high and very high at $34.7 \%$. So, it can be seen that categorization with the highest percentage is in the very high and high addition categorization.

It can be interpreted that in the number of percentages in IT dedication and non IT dedication is more dominant high categorization. This can be caused because the IT and Non IT divisions have an enthusiasm in each of their jobs, and also feel that the work they are working on is a challenge for them to solve and they assume that their work is a challenge. For example, in the IT division, the majority of workers are predominantly male. They feel that the work in the IT division is a challenge for them to complete their program work. One of the IT Division is the network engineer part which plays a major role in overcoming the server and network that exists in a company. Likewise, the Non IT division which is more dominant in its workforce is women, who usually work as marketing, finance and so on. To work as a marketing is a challenge for them to achieve sales targets, so they are very enthusiastic about the work they work for, as well as finance, which plays an important role in the company in financial management. The finance department is also a challenging job for employees to be careful and there are no mistakes in managing finances.

Absorption on IT and Non IT division. The following frequency of calculation results based on the above categorization determination formula is divided into 5 categorizations on the level of dedication in the IT and Non IT divisions. For details, see the table

Table 5: Categorization of Differences in Absorption Levels in IT and Non IT divisions

\begin{tabular}{|l|l|l|}
\hline Categorization & IT Absorption & NonIT Absorption \\
\hline Very low & $8.8 \%$ & $9.2 \%$ \\
\hline Low & $16.9 \%$ & $19.4 \%$ \\
\hline Neutral & $47.4 \%$ & $42.9 \%$ \\
\hline High & $23.5 \%$ & $21.4 \%$ \\
\hline Very high & $3.3 \%$ & $7.1 \%$ \\
\hline Total & $100 \%$ & $100 \%$ \\
\hline
\end{tabular}

Source: results of questionnaire data

on the highest IT absorption dimension that is found in moderate categorization, the percentage is $47.4 \%$ and the lowest is very high categorization with $3.3 \%$ percentages. Whereas in the count the number between very low and low is $25.7 \%$, and for the addition of high and very high is $26.8 \%$. So, it can be seen that categorization with the highest percentage is in the very high and high addition categorization. Then it can be seen in the highest categorization of Non IT absorption categories, which are found in the medium categorization, where the percentage is $42.9 \%$ and the lowest is very high categorization with $7.1 \%$ percent. Whereas in the count the number between very low and low is $28.6 \%$, and for the addition of high and very high, which is $28.5 \%$.

So, it can be seen that categorization with the highest percentage is in the very low and low addition categorization. D apat mean that a tip on IT more demoninan absorption at high categorization. While non IT absorption is more dominant in the low category. This is due to because IT division employees feel that their work just goes away when they do work. With enthusiasm they are at work so that employees feel happy when they work intensively. While Non IT absorption feels that they are not happy with what they are doing and also do not reflect readiness to serve their willingness to work and for the T test itself there is no significant difference in the level of work engagement related to the IT and non -IT divisions, nor is there a significant difference in the level of vigor, dedication and absorptions related to the IT and Non-IT divisions.

\section{Findings}

In this study there are results that have no significant difference between work engagement related to the IT and non IT divisions, the level of vigor between the IT and Non IT divisions, the level of dedication between the IT and non IT divisions and absorption between the IT and Non IT divisions 


\title{
International Advanced Research Journal in Science, Engineering and Technology
}

\author{
Vol. 6, Issue 3, March 2019
}

\section{CONCLUSION}

Information technology companies have work engagement in each division, both IT and Non IT divisions. With the work engagement, if the work engagement is high, it will motivate someone to work in commitment, enthusiasm, competence, and enthusiasm. There are more engagement members in the IT and Non IT divisions in information technology companies. But for the IT and Non IT divisions, high work engagement is in the Non IT division. It is in the non-IT division with a fairly young age, and have a sense of enthusiasm, enthusiasm, and appreciation in doing the work they do, one example of this aims to meet the personal needs of those who are still in school while working, earning income for can further education. On work engagement there are dimensions, among others, the dominant dominant low vigor . but the dimensions of dedication and absorption are also more dominant. This can be confirmed because there are still many employees who are lazy to come to work and work. but the dimensions of dedication and absorption for categorization are more dominant, namely high categorization. This is due to factors from employees who consider their work to inspire themselves and also feel that work goes away while working. In IT vigor the dominant is low. Whereas for non IT vigor is more dominant. This characteristic can be demonstrated by lack of zeal in the morning, doing work in idleness, and can also be affected by the background they have as IT but in attitudes and traits unlike IT people and there is no sense of resilience in doing work. For Non IT, this can be caused by employees having a high sense of responsibility and enthusiasm, and can also be caused because employees who are high school graduates are still passionate about finding jobs that can be a factor in tuition fees. In IT dedication and non IT dedication is more dominant. This can be caused because the IT and Non IT divisions have an enthusiasm in each of their jobs, and also feel that the work they are working on is a challenge for them to solve and they assume that their work is a challenge. IT absorption is more dominant. While non IT absorption more low profile. This is due to because IT division employees feel that their work just goes away when they do work. With enthusiasm they are at work so that employees feel happy when they work intensively. While Non IT Absorption feels that they are not happy with what they are doing and also do not reflect readiness to serve their willingness to work. Whereas in conducting different tests, there is an analysis of differences in the level of work engagement between IT and non IT divisions in IT companies, there is no significant difference. For example, the level of dimensions of vigor, dedication and absorption in the IT and non-IT divisions is that there are no significant differences. In this study there are several limitations that can be considered for further research. This study uses a questionnaire as a measurement tool that can be filled by respondents. However, the questionnaire has limitations as usual in filling out statements. There is a possibility that the respondents did not fill out the truth or only filled in based on the ideal conditions expected and not the actual conditions that were happening. In addition, limitations on the scale of the questionnaire, namely in the questionnaire of this study using a very low, low, medium, high, and very high scale so that it is likely that many respondents feel doubtful about what they feel then choose with moderate answers. Suggestions for further research can use other variables to influence the IT and Non IT divisions in a company or can be with the same variable but with different industries.

\section{REFERENCES}

[1]. Agustian, AG Engagement and poison of organizational culture . ESQ News. Retrieved from http://esq-news.com (2012).

[2]. Aini, FAF, Hardjajani, T., Priyatama, AN 2014. Relation between Quality of Interaction-Subordinate Interaction and Quality of Work Life with Organizational Citizenship Behavior at PT. Air Mancur Palur Karanganyar. Discourse Journal of Psychology . Vol. 6. No. 11 (55-72).

[3]. Bakker, AB, \& Demerouti, E. Towards a model of work engagement . Career Development International, 13 (3), 209-223. (2008)

[4]. Bakker, Arnold. B., Leiter, Michael. P. (2010). Work Engagement: A Handbook of Essential Theory and Research. New York: Psychology Press.

[5]. Bakker, BA (2011). Engagement and job crafting: Engaged employees create their own great place to work , USA: New Horizons in Management.

[6]. Bakker, AB, Schaufeli, WB, Leiter, MP, \& Taris, TW. "Work Engagement: An Emerging Concept in Occupational Health Psychology". Journal of Work \& Stress , 187-200 (2008)

[7]. Human Capital Journal, (2014), Indonesia's Highest Employee engagement, article 1 September 2014, from http: // human capital journal.com/ employee-engagement-indonesia-highest /, accessed 1 September 2016

[8]. Field, LK, \& Buitendach, JH. "Happiness, work engagement commitment of support staff at tertiary education institution in South Africa". SA Journal of Industrial Psychology / SA Tydskrif vir Bedryfsielkunde , 37 (1), Art. (2011)

[9]. Finney, MI (2010). Engagement: A Smart Way to Make Employees Spill the Best Capabilities for the Company. Translator: Verawaty Pakpahan. Jakarta: PPM Publisher. Mcleod, David \& Clarke, Nita. 2009. Engaging for Success: enhaning performance through employee engagement. UK: MGP Book Group.

[10]. Conquer Meirlyn \& Customs Hana. "Work engagement of MRN employees on the implementation of HR analysis data application". scientific journal psychology MANASA, Vol . 5, No.1, 1-14. (2016)

[11]. Mujiasih, Endah. 2015. Relationship between perceived organizational support and employee engagement. Undip Psychology Journal Vol. 14 No.1 April 2015, 40 - 51

[12]. Sugiyono. (2014). Educational Research Methods Quantitative Approach, Qualitative DanR D . Bandung: Alfabeta.

[13]. Tintien. 2016. Preparation and Development of Employee Engagement Measurement Tools. Journal of Psychology Vol. 1 No. 1, November 2016, 113-130. Yogyakarya: Gajah Mada University

[14]. Wahyu, H andoyo., Agnes \& Setawan, Roy. 2017. Effect of Emplotee Engagement on Employee Performance at PT. Tirta Rejeki Dewata. AGORA. Vol. 5, No.1 